\title{
Colonisation of babies and their families by group B streptococci
}

\author{
A $M$ WEINDLING, J M HAWKINS, M A COOMBES, J STRINGER
}

\begin{abstract}
A high incidence of group B streptococcal disease of the newborn in West Berkshire led to a prospective study of the condition. Cultures taken from 1090 babies shortly after birth showed that $65(6 \%)$ were colonised with the streptococcus. Thirty of these babies were assigned to group 1. Bacteriological samples were taken from babies and mothers at birth and at four, eight, and 12 weeks, and also from fathers and siblings. Fifty uncolonised babies and their families were similarly studied and served as controls (group 2).

In group 1, 28 of the 30 mothers and 14 of the 28 fathers examined were colonised by group B streptococci. In group 2 the streptococci were isolated from three babies, 12 mothers, and 11 out of 45 fathers during follow-up.

These findings suggest that group B streptococci are carried predominantly in the lower gastrointestinal and genitourinary tracts. Most families are lightly colonised, but in others maternal colonisation is stable and heavy and the incidence of paternal colonisation high. Results of serotyping suggest that sexual transmission occurs, which may explain the difficulty in eradicating the organism during pregnancy.
\end{abstract}

\section{Introduction}

The potential pathogenicity of the group B streptococcus is not in doubt, and a clinical problem that faces obstetricians and paediatricians is how best to manage mother and baby when one

Royal Berkshire Hospital, Reading, Berks RG1 5AN

A $M$ WEINDLING, BSC, MRCP, paediatric registrar (now research fellow, university department of paediatrics, Oxford)

J M HAWKINS, MRCPATH, consultant microbiologist

M A COOMBES, FIMLS, chief medical laboratory scientific officer, department of microbiology

Streptococcus Reference Unit, Central Public Health Laboratory, Colindale, London NW9 5HT

J STRINGER, PHD, senior microbiologist or other is colonised with the organism. Such management is, however, hampered by lack of information about normal patterns of colonisation of families in Britain.

In 1978 in West Berkshire seven cases of early-onset group B streptococcal infection occurred resulting in the deaths of four babies. The seven infections represented an incidence of 14 cases/10000 live births compared with an overall figure of 2.9/10 000 live births in England and Wales (R T Mayon-White, personal communication). Concern over this apparently local high incidence led to a prospective study to determine the rate of acquisition of group B streptococci by infants at birth, investigate the distribution of the organism in the family, and discover the difference in carriage at different anatomical sites.

\section{Methods}

The study was conducted between July 1979 and February 1980. Swabs of the external ear and anal verge were taken within the first 24 hours of life from 1090 unselected babies born at the Royal Berkshire Hospital. These two sites are apparently ${ }^{2}$ the most favourable in the early neonatal period. Other sites were occasionally sampled if the baby was ill, and babies were considered to be colonised when group B streptococci were isolated from at least one site.

Swabbing of babies was continued until 30 colonised babies were available for follow-up and could be assigned to group 1. Fifty uncolonised babies born at about the same time were randomly chosen as controls and assigned to group 2. Selection for the two groups depended on the parents' agreeing to participate, on their living within 10 miles $(16 \mathrm{~km})$ of the hospital, and on their having a telephone at home.

Cultures from the baby were identified after 18-24 hours of incubation, and low vaginal swabs and anal swabs were then taken from the mothers. The follow-up procedure consisted in a home visit within the first month, usually in the fourth week, and again when the baby was 8 and 12 weeks old. Bacteriological samples were taken from mother and baby at each visit, and on a single occasion from father and siblings. Sites of sampling were ear, anal verge, and throat in the babies; low vagina, anus, nose, and throat in the mothers; tip of urethra, anus, nose, and throat in the fathers; and anus, nose, and throat in siblings.

Bacteriological-Sterile cotton-tipped, albumin-dipped swabs (Hospiswabs) moistened with saline were used throughout. Each swab was transferred to the laboratory in Todd-Hewitt broth supplemented with half-strength Oxoid blood agar base No 2 , horse serum $(5 \% \mathrm{v} / \mathrm{v})$, nalidixic acid $(15 \mathrm{mg} / \mathrm{l})$, and neomycin 
(30 $\mathrm{mg} / \mathrm{l})$. The swabs were inoculated on to Columbia blood agar plates supplemented with defibrinated horse blood $(10 \% \mathrm{v} / \mathrm{v})$, nalidixic acid, and neomycin. The plates were incubated anaerobically and examined daily for three days before being discarded. All presumptive group B streptococci were grouped by coagglutination using the Phadebact streptococcus identification test (Pharmacia Ltd, Sweden). Strains that gave a positive group B reaction were sent to the Streptococcus Reference Unit. Isolates were serotyped by precipitation tests in $\mathrm{gel}^{3}$ and phage typed.

\section{Results}

Table I summarises the clinical details of the mothers and babies studied. There were no significant differences in birth weight, gestational age, maternal age, number of vaginal examinations performed, application of fetal scalp electrodes, and duration of labour (Student's $t$ test) or mode of delivery ( $\chi^{2}$ test with Yates's correction) between babies colonised by group B streptococci at birth and those not colonised.

Group B streptococci were isolated from $65(6 \%)$ of the 1090 babies sampled. In all cases the isolates from each mother and baby were identical by serotype and phage pattern.

\section{MOTHERS}

Of the 30 mothers in group 1,25 were sampled within 48 hours after delivery; of these, $21(84 \%)$ were carrying the streptococcus. The four mothers with negative cultures had been given ampicillin before or during labour, but this did not prevent acquisition of the organism by their babies; two of these mothers became colonised within the next four weeks, and two remained uncolonised throughout. Of the five mothers not sampled shortly after birth, all were colonised by two weeks post partum. Twenty-two of the 30 mothers in this group were still colonised with the same strain of group B streptococci at 12 weeks.

Table II lists the sites of colonisation by the organism. After delivery the low vaginal swab gave the best yield in mothers in group 1 , with the anal site second; after 12 weeks this pattern was reversed. Carriage in the throat was rare, and there were no nasal carriers.

Six of the 50 mothers in group 2 were colonised after delivery, though their babies were not contaminated; two were still carriers at 12 weeks. Four mothers acquired the organism during the study, so that by the end of 12 weeks again six mothers were colonised. Overall 12 mothers in group 2 were detected as carriers at some time during the study.

\section{BABIES}

Of the 65 babies who were colonised with group B streptococci after birth, 11 became ill with respiratory distress or apnoea. In only one case did blood culture give a positive result, and this baby, treated with penicillin, survived. Two babies died, but in both cases the organism was isolated from surface cultures only: one was born prematurely at 28 weeks of gestation after membranes had been ruptured for 12 days, and the other had suffered severe intrapartum asphyxia. Six of these 11 babies were included in group 1, and five had been treated with penicillin; four babies lost the organism after treatment, but one of these became recolonised after a week and remained so; the fifth did not lose the organism after treatment and remained colonised throughout; the sixth recovered spontaneously.

Eighteen $(60 \%)$ of the 30 babies who were colonised at birth were still colonised at four weeks, and $12(40 \%)$ were colonised at 12 weeks. Table III shows the sites of colonisation: all anal swabs but only half
TABLE II-Sites of colonisation of mothers by group B streptococci

\begin{tabular}{lcccc}
\hline & $\begin{array}{c}\text { Low } \\
\text { vaginal } \\
\text { swab }\end{array}$ & Anus & Throat & Nose \\
\hline Group 1 $\left\{\begin{array}{l}\text { Post partum }(n=21) \\
\text { At 12 weeks }(n=22)\end{array}\right.$ & 20 & 11 & NA & NA \\
Post partum $(n=6)$ & 13 & 17 & 1 & 0 \\
At 12 weeks $(n=6)$ & 3 & 5 & NA & NA \\
Group & 5 & 6 & 0 & 0 \\
\hline
\end{tabular}

NA $=$ Not applicable

TABLE III-Sites of colonisation of babies by group B streptococci

\begin{tabular}{|c|c|c|c|c|}
\hline & Anus & Ear & Throat & Nose \\
\hline $\begin{array}{l}\text { Group } 1\left\{\begin{array}{l}\text { After birth }(n=30) \\
\text { Aged } 12 \text { weeks }(n=12)\end{array}\right. \\
\text { Group } 2 \\
\text { Birth to } 12 \text { weeks }(n=3)\end{array}$ & $\begin{array}{c}29 / 29 * \\
10 \\
3\end{array}$ & $\begin{array}{r}15 \\
0 \\
0\end{array}$ & $\begin{array}{c}\text { NA } \\
8 \\
1\end{array}$ & $\begin{array}{c}\text { NA } \\
0 \\
0\end{array}$ \\
\hline
\end{tabular}

NA $=$ Not applicable.

* Pharyngeal aspirate instead of anal swab taken in one case.

TABLE IV-Sites of colonisation of fathers by group B streptococci

\begin{tabular}{lcccc}
\hline & & \multicolumn{3}{c}{ No positive/No colonised } \\
\cline { 3 - 5 } & colonised & Anus & Urethra & Throat/nose \\
\hline Group 1 $(n=28)$ & 14 & $11 / 14$ & $7 / 14$ & $3 / 14$ \\
Group 2 $(n=45)$ & 11 & $10 / 11$ & $5 / 11$ & $2 / 11$ \\
\hline
\end{tabular}

of the ear swabs were culture-positive at birth. After 12 weeks anal carriage still predominated, but carriage in the throat occurred in two-thirds of the babies still colonised. No babies in this group developed "late-onset" disease.

Three of the 50 babies who were not colonised with group B streptococci at birth (group 2) acquired the organism during the study. This occurred at six and 12 weeks in two babies and was unrelated to maternal carriage; the third baby had acquired the organism by four weeks, and all other members of his family were heavily colonised with a type 1a strain. Babies from 15 other families in whom other members were colonised did not acquire the organism during the 12-week sampling period.

\section{FATHERS}

Swabs were obtained from 28 of the 30 fathers in group 1 and 45 of the 50 in group 2 . Fourteen $(50 \%)$ of the fathers in group 1 were colonised compared with $11(24 \%)$ in group 2 (table IV). Of all culture-positive swabs from fathers in the two groups, $21(84 \%)$ were from the anus, $12(48 \%)$ from the urethra, and $3(12 \%)$ from the throat. Nasal carriage occurred in three fathers but not in any other family member. In all cases the strains isolated from the fathers' urethral swabs were indistinguishable, both serologically and by phage type, from the isolates of their wives.

\section{BROTHERS AND SISTERS}

All children were sampled. Only $3(18 \%)$ were carriers in group 1 and $3(9 \%)$ carriers in group 2 . Again the anus was the commonest site of colonisation.

TABLE I-Clinical details of mothers and babies

\begin{tabular}{|c|c|c|c|c|c|c|c|c|c|c|c|c|}
\hline & \multirow{2}{*}{ No } & \multicolumn{2}{|c|}{ Sex } & \multirow{2}{*}{$\begin{array}{l}\text { Mean birth } \\
\text { weight } \pm S D \\
(\mathrm{~g})\end{array}$} & \multirow{2}{*}{$\begin{array}{c}\text { Mean } \\
\text { gestational } \\
\text { age } \\
\text { (weeks) }\end{array}$} & \multirow{2}{*}{$\begin{array}{l}\text { Mean maternal } \\
\text { age }+ \text { SD } \\
\text { (years) }\end{array}$} & \multirow{2}{*}{$\begin{array}{l}\text { Mean No of } \\
\text { vaginal } \\
\text { examinations } \\
\pm S D\end{array}$} & \multirow{2}{*}{$\begin{array}{c}\text { Mean } \\
\text { duration of } \\
\text { labour } \pm S D \\
\text { (hours) }\end{array}$} & \multirow{2}{*}{$\begin{array}{l}\text { Use of fetal } \\
\text { scalp electrode* }\end{array}$} & \multicolumn{3}{|c|}{ Mode of delivery } \\
\hline & & $M$ & $\mathrm{~F}$ & & & & & & & $\begin{array}{l}\text { Spontaneous } \\
\text { vertex }\end{array}$ & Forceps & $\begin{array}{c}\text { Caesarean } \\
\text { section }\end{array}$ \\
\hline $\begin{array}{l}\text { Group } 1 \\
\text { Group } 2\end{array}$ & $\begin{array}{l}30 \\
50\end{array}$ & $\begin{array}{l}14\left(47^{\circ}{ }^{\circ}\right) \\
23\left(46^{\circ}{ }_{0}\right)\end{array}$ & $\begin{array}{l}16\left(53^{\circ}{ }_{0}\right) \\
27\left(54^{\circ}{ }_{0}\right)\end{array}$ & $\begin{array}{l}3390 \pm 530 \\
3362 \pm 444\end{array}$ & $\begin{array}{l}38 \\
38\end{array}$ & $\begin{array}{l}29 \cdot 0 \pm 4 \cdot 2 \\
27 \cdot 0 \pm 5 \cdot 0\end{array}$ & $\begin{array}{l}2 \cdot 3 \pm 1 \cdot 1 \\
2 \cdot 1 \pm 1 \cdot 3\end{array}$ & $\begin{array}{l}5 \cdot 2 \pm 5 \cdot 8 \\
6 \cdot 1 \pm 4 \cdot 4\end{array}$ & $\begin{array}{l}10 / 18\left(56^{\circ} \%\right) \\
25 / 44\left(57^{\circ}\right)\end{array}$ & $\begin{array}{l}22 \\
36\end{array}$ & $\begin{array}{l}8 \\
9\end{array}$ & $\begin{array}{l}0 \\
5\end{array}$ \\
\hline
\end{tabular}

*Whether a scalp electrode was applied was known in only 18 cases in group 1 and 44 cases in group 2. 
FAMILIES

During the study cultures were taken from 177 members of the 50 control families, and $29\left(16^{\circ}{ }_{0}\right)$ grew group B streptococci. In contrast, out of 102 members of the families in group 1 who were sampled, 50 $\left(49^{\circ}{ }_{1}\right)$ were positive for the organism. The distribution of positive swabs (tables II-IV) showed that carriage of the organism was predominantly in the lower gastrointestinal and genitourinary tracts.

\section{Discussion}

On another occasion we found that the carriage rate of group B streptococci by mothers in labour in this district was $12.7 \%$ (unpublished observations) compared with rates of between $2 \cdot 3^{\circ}$, and $25.4 \%$ reported elsewhere. ${ }^{25-7}$ The neonatal acquisition rate of $6 \%$ found in this study falls at the lower end of a range of between $3 \%$ and $26 \%{ }^{8}$

Our results suggest that there may be two patterns of colonisation by group B streptococci in the community. The commonest is probably of families who are either uncolonised or transiently and relatively lightly colonised; colonised mothers do not seem to contaminate their babies, but persistent colonisation of mothers is usually associated with paternal carriage. The second pattern is that some families-probably less than $6 \%$-seem to show stable, heavy colonisation of the mother together with a high incidence of paternal colonisation by the same strain of the organism. This is compatible with good health in both. Such mothers are likely to contaminate their infants at birth, but most of the babies remain well. At home the colonised baby gradually loses the organism until the low carriage rate of brothers and sisters is reached; siblings apparently do not play an important part in family colonisation. The favoured site of colonisation seems to be the anorectal region with vaginal contamination and subsequent transmission to the sexual partner; the paternal carriage rate of $24 \%$ among babies uncolonised at birth was virtually identical with that reported by Bergqvist et $a l^{9}$ among healthy male medical students in Sweden, but the colonisation rate of fathers of babies from whom group B streptococci were isolated at birth was twice as high $\left(50^{\circ}\right)$. This observation has not been reported before and may be significant in identifying a reservoir of the infection in the community.

Various suggestions for preventing neonatal group B streptococcal infection have been made. Our evidence of probable family colonisation might explain the failure of attempts to eliminate the organism during pregnancy. ${ }^{210}$ Four mothers with negative cultures at birth had had intravenous ampicillin either immediately before or during labour. Their babies were not only colonised but developed a respiratory illness. Our findings do not therefore support the view that ampicillin administered to the mother during labour may prevent the baby acquiring the streptococcus. ${ }^{11}$ Steigman $e t a l^{12}$ and Siegel et $a l^{13}$ suggested that all babies should be given a parenteral injection of penicillin after birth. In our population this would result in a large number of babies being given this drug unnecessarily and a possible concomitant increase in the incidence of disease caused by penicillin-resistant pathogens. ${ }^{13}$ In view of the fact that, unlike other studies, ${ }^{14}{ }^{15-17}$ we found no evidence of nosocomial infection during the study, isolating mothers and babies who are colonised with group B streptococci is also not justified.

A safe and reasonable approach is to suspect group B streptococcal infection in all cases of neonatal respiratory disease ${ }^{18}$ or other unexplained illness (temperature instability or hypoglycaemia) $)^{19}$ and to take appropriate bacteriological specimens, including anal swabs, and give large doses of penicillin parenterally. This approach may well have contributed to the lack of deaths among the babies studied, despite one of them having septicaemia.

We thank Dr D G H Stone for help and advice; Dr W R Maxted and Dr R T Mayon-White, Public Health Laboratory Service, for advice in designing the study; the staff of the maternity unit, Royal Berkshire
Hospital, and particularly the paediatric residents; and Drs C J Fulford, E M Steven, J R Webster, and J M Perl, who collected the specimens in the community.

Requests for reprints should be addressed to: $\operatorname{Dr} A M$ Weindling, University Department of Paediatrics, John Radcliffe Hospital, Oxford OX3 9DU.

This study was supported by a grant from the locally organised research fund of the Oxford Regional Health Authority.

\section{References}

${ }^{1}$ Ferreiri P, Cleary PP, Seeds AE. Epidemiology of group-B streptococcal carriage in pregnant women and newborn infants. $\mathcal{F}$ Med Microbiol $1977 ; 10: 103-14$

2 Franciosi RA, Knostman JD, Zimmermanns RA. Group B streptococcal and infant infections. $\mathcal{F}$ Pediatr 1973;82:707-18

${ }^{3}$ Rotta J, Krause RM, Lancefield RC, Everly W, Lackland H. New approaches for the laboratory recognition of $M$-types of group-A streptococci. F Exp Med 1971;134:1298-1315.

4 Stringer J. The development of a phage-typing system for group-B streptococci. F Med Microbiol 1980;13:133-43.

${ }^{5}$ Hood M, Janney A, Dameron G. Beta-hemolytic streptococcus group B associated with problems of the perinatal period. Am $\mathcal{F}$ Obstet Gynecol $1961 ; 82: 809-18$.

${ }^{6}$ Baker CJ, Barrett FF. Transmission of group B streptococci among parturient women and their neonates. F Pediatr 1973;83:919-25.

${ }^{7}$ Reid TMS. Emergence of group B streptococci in obstetric and perinatal infections. $\mathrm{Br} \mathrm{Med} \mathcal{F} 1975 ; \mathrm{ii}: 533-6$.

${ }^{8}$ Speck WT, Driscoll JM, Polin RA, Rosenkranz HS. Natural history of neonatal colonization with group-B streptococci. Pediatrics 1977;60: 356-9.

${ }^{9}$ Bergqvist G, Hurvell B, Thal E, Vaclavinkova V. The persistence of group B streptococci in families. Scand $\mathcal{F}$ Infect Dis 1976;8:79-81.

10 Hall RT, Barnes W, Krishnan L, et al. Antibiotic treatment of parturient women colonised with group B streptococci. Am $\mathcal{F}$ Obstet Gynecol 1976; $124: 630-3$.

11 Yow MD, Mason EO, Leeds LJ, Thompson PK, Clark DJ, Gardner SE. Ampicillin prevents intrapartum transmission of group B streptococcus. f $A M A$ 1979;241:1245-7.

12 Steigman AJ, Bottone EJ, Hanna BA. Does intramuscular penicillin at delivery prevent group B beta hemolytic streptococcal disease of the newborn infant? $\mathcal{F}$ Pediatr 1975;87:496.

${ }^{13}$ Siegel JD, McCracken GH, Threlkeld N, Milvenan B, Rosenfeld CR. Single dose penicillin prophylaxis against neonatal group-B streptococcal infections. N Engl f Med 1980;303:769-75.

14 Steere AC, Aber RC, Warford LR, et al. Possible nosocomial transmission of group-B streptococci in a newborn nursery. $\mathcal{F}$ Pediatr 1975;87:784-7.

${ }^{15}$ Aber RC, Allen N, Howell JT, Wilkinson HW, Facklam RR. Nosocomial transmission of group-B streptococci. Pediatrics 1976;58:346-53.

16 Paredes A, Wong P, Mason EO Jr, Taber LH. Nosocomial transmission of group-B streptococci in a newborn nursery. Pediatrics 1977;59: 679-82.

17 Easmon CSF, Hastings MJG, Clare AJ, et al. Nosocomial transmission of group B streptococci. Br Med f $1981 ; 283: 459-61$.

18 Wilkinson HW. Group B streptococcal infection in humans. Annu Rev Microbiol 1978;32:41-57.

19 Ablow RC, Driscoll SG, Effman EL, et al. A comparison of early-onset group-B streptococcal neonatal infection and the respiratory distress syndrome of the newborn. N Engl F Med 1976;294:65-70.

(Accepted 28 August 1981)

DRAGONS are so well known to every one that plants them in their gardens, they need no description; if not, let them look down to the lower end of the stalks, and see how like a snake they look.

The plant is under the dominion of Mars, and therefore it would be a wonder if it should want some obnoxious quality or other: In all herbs of that quality, the safest way is either to distil the herb in an alembick, in what vehicle you please, or else to press out the juice, and distil that in a glass still, in sand. It scours and cleanses the internal parts of the body mightily, and it clears the external parts also, being externally applied, from freckles, morphew, and sunburning: Your best way to use it externally, is to mix it with vinegar ; an ointment of it is held to be good in wounds and ulcers; it consumes cankers, and that flesh growing in the nostrils, which they call Polypus; Also the distilled water being dropped into the eyes, takes away spots there, or the pin and web, and mends the dimness of sight; it is excellently good against pestilence and poison. Pliny and Dioscorides affirm, that no serpent will meddle with him that carries this herb about him. (Nicholas Culpeper (1616-54) The Complete Herbal, 1850.) 